\title{
VALUASI EKONOMI ALTERNATIF TEKNOLOGI PENGELOLAAN SAMPAH PERKOTAAN
}

\author{
Haikal Rahman \\ Fakultas Teknik, Universitas Negeri Medan \\ Jl. Williem Iskandar Ps. V Medan 20221, Telp. +6261-6613365 \\ Email: haikalrahman@unimed.in
}

\begin{abstract}
This study is specifically aims to elaborate on the economic valuation that consists of: (1) Investment costs and (2) Operating Costs of the alternative waste management technology which can be applied to the final processing of Municipalities Solid Waste. The results of the simulation shows that the Biodrying with the combination of Incenerator or Gasification is the technology that has the least operational costs with an average of 10.907 million Euro per year of its operational costs. On the other hand the Aerobic MBT (Mechanical Biological Treatment) without the production of RDF (refuse Derivative Fuel) technology is a technology that requires the highest operational costs with an average of 15,808 million Euro per year. In terms of the initial investment costs both Biological Treatment technology has the lower value compare to the two Thermal Treatment technologies.
\end{abstract}

Key words: Economic Valuation, Municipalities Solid Waste Management, Technologies

\section{PENDAHULUAN}

ampah perkotaan (SP) didefinisikan sebagai sampah yang dikumpulkan oleh pemerintahan kota atau biasa disebut dengan sektor formal (SF). SP terdiri dari sampah yang berasal dari rumah tangga, perkantoran, pasar, dan jalanan. Sedangkan Sistem Pengelolaan Sampah Perkotaan (SPSP) dapat didefinisikan sebagai suatu upaya pengelolaan yang meliputi proses pemisahan, pengumpulan, pemindahan pengangkutan dan pembuangan SP yang bertujuan untuk menjaga kesehatan masyarakat, meningkatkan keberlanjutan dan kualitas lingkungan, meningkatkan produktivitas ekonomi serta menambah jumlah angkatan kerja (Schübeler et al., 1996 ; EC, 2000 ; Dubois et al., 2004)

Sumber penghasil sampah di Indonesia sebagian besar berasal dari perumahan (70-75\%) dan (25-30\%) berasal dari non perumahan (WBIO, 2003) Secara umum komposisi sampah terdiri dari jenis organik, kertas, plastik, gelas, logam dan lain-lain. Sampah di Indonesia rata-rata masuk dalam kategori sampah basah yang dengan kandungan organik cukup tinggi (70-80\%) dan anorganiknya (20-30\%) serta memiliki 
kadar air 60\%, berat jenis rata-rata $250 \mathrm{~kg} / \mathrm{m} 3$ serta nilai kalor (1.100-1.500) k.cal/kg. Sampah ini akan terdekomposisi menjadi bentuk padat, cair dan gas.

Apabila ditinjau dari aspek ekonomi pengelolaan sampah perkotaaan tentunya akan sangat berkaitan erat dengan layanan jasa yang harus diberikan sebagai akibat dari adanya aktivitas ekonomi, efektivitas biaya sistem pengelolaan sampah perkotaan (SPSP), dimensi makro-ekonomi dari penggunaan sumber daya dan konservasi serta pendapatan yang diperoleh dari layanan jasa yang diberikan (Schubler et al., 1996). Keterkaitan ini disebabkan karena :

1. Jumlah timbulan sampah serta permintaan layanan pengelolaan yang terus meningkat serta bersinergi dengan meningkatnya ekonomi.

2. Rendahnya biaya pelayanan yang diberikan akan berdampak kepada menurunnya kualitas lingkungan.

3. Efektivitas SPSP sangat bergantung pada biaya siklus hidup fasilitas dan peralatan jangka panjang serta dampak ekonomi terhadap layanan yang diberikan. Oleh karenanya, evaluasi ekonomi merupakan masukan yang penting untuk perencanaan strategis dan investasi bagi SPSP.

Berkaitan dengan siklus hidup fasilitas dan peralatan jangka panjang dari suatu SPSP tentunya tidak terlepas dari sisi teknologi pengelolaan sampah yang diterapkan pada pengelolaan akhir sampah perkotaan. Alternatif teknologi pengelolaan SP tersebut dapat disarikan kedalam beberapa kategori teknologi pengelolaan yang terdiri dari : (1) Biological yang terbagi atas 2 kategori: (a) Anaerobic Digestion dan (b) Composting; (2) Mechanical - Material Recover Facilities (MRF) ; (3) Thermal yang terbagi atas 2 katergori: (a) Advance Thermal Treatment ; (b) Incenerationserta (4) Hybrid-Bio Mechanical Treatment (Mclanaghan,2002; Klein, 2002;Münnich et al, 2006; Last, 2008, Economopoulos,2009). Studi ini secara khusus bertujuan untuk mengelaborasi nilai ekonomis yang terdiri dari : (1) Biaya Investasi dan (2) Biaya Operasionaldari altenatif teknologi pengelolaan sampah yang dapat diterapkan pada pemrosesan akhir sampah perkotaan.

\section{METODOLOGI}

Valuasi ekonomi terhadap alternatif teknologi pengelolaan sampah perkotaan ini dilakukan dengan menggunakan pendekatan sistem dinamis.Tasrif (2005) menyebutkan bahwa kriteria yang tepat untuk menggunakan pendekatan sistem dinamis diantaranya adalah memiliki sifat dinamis (berubah terhadap waktu). Simulasi dilakukan dengan menggunakan bantuan perangkat lunak PowerSim 2005 Express Edition (PowerSim, 2005) dengan batasan waktu 20 tahun yang ditentukan secara purposive. Pendekatan sistem dinamisyang didasarkan atas formulasi matematis dari setiap alternatif teknologi pengelolaan(Economopoulos,2009) tersebut selanjutnya membutuhkan variabel jumlah timbulan sampah dinamis yang merupakan variabel input dari alternatif teknologi pengelolaan yang ada. Data jumlah timbulan sampah tersebut diambil dari data dinamis jumlah timbulan sampah perkotaan di kota Medan (Rahman et al, 2009, Rahman, 2011). 


\section{FUNGSI BIAYA ALTERNATIF TEKNOLOGI PENGELOLAAN}

Fungsi biaya dari setiap alternatif teknologi pengelolaan (Economopoulos,2009) disarikan dari berbagi literatur yang merupakan hasil penelitian dari berbagai konsultan independen yang terdapat di Uni Eropa seperti Juniper ConsultancyServices Ltd. (2005), Eunomia Research and Consulting (2000, 2002) dan Tsilemou dan Panagiotakopoulos $(2006,2007)$ seperti yang disajikan pada Tabel 1 berikut ini.

Tabel 1. Fungsi Biaya Alternatif Teknologi Pengelolaan

\begin{tabular}{|c|c|c|}
\hline Alaternatif Teknologi & $\begin{array}{c}\text { Kapasitas Pengolahan } \\
\text { (Ton/thn) }\end{array}$ & Fungsi Biaya \\
\hline \multicolumn{3}{|c|}{ Investasi Awal } \\
\hline $\begin{array}{l}\text { Aerobic MBT without RDF } \\
\text { recovery }\end{array}$ & $250,000-500,000$ & $100,884 x+10,671,977$ \\
\hline Aerobic MBT with RDF recovery & $250,000-500,000$ & $118,976 x+10,339,650$ \\
\hline Incineration & $50,000-500,000$ & $1750,341 x^{0.800}$ \\
\hline $\begin{array}{l}\text { Biodrying + incineration or } \\
\text { gasification }\end{array}$ & $50,000-500,000$ & $1961,385 x^{0.884}$ \\
\hline \multicolumn{3}{|c|}{ Biaya Operasional ( $€ /$ tahun) } \\
\hline $\begin{array}{l}\text { Aerobic MBT without RDF } \\
\text { recovery }\end{array}$ & $50,000-500,000$ & $32,353 x+1608,123$ \\
\hline Aerobic MBT with RDF recovery & $50,000-500,000$ & $27,647 x+1786,291$ \\
\hline Incineration & $50,000-500,000$ & $120,903 x^{0.700}$ \\
\hline $\begin{array}{l}\text { Biodrying + incineration or } \\
\text { gasification }\end{array}$ & $50,000-500,000$ & $117,838 x^{0.873}$ \\
\hline
\end{tabular}

Sumber : (Economopoulos, 2009)

Keterangan : $\mathrm{x}$ = jumlah sampah yang diolah

\section{TIMBULAN SAMPAH DINAMIS}

Tabel 1 diatas memperlihatkan bahwa fungsi biaya dari berbagai alternatif teknlogi pengelolaan diatas membutuhkan nilai $\mathrm{x}$ yang merupakan jumlah sampah yang dapat diolah oleh kompilasi alternatif teknologi pengelolaan diatas. Oleh karena valuasi ekonomi ini menggunakan pendekatan dinamis maka tentunya dibutuhkan data timbulan sampah yang dinamis (berubah terhadap waktu).

Data timbulan sampah dinamis ini diperoleh dari model dinamis jumlah timbulan sampah perkotaan (Rahman et al, 2009, Rahman, 2011) yang merupakan jumlah timbulan sampah perkotaan di Kota Medan. Gambar 1 berikut memperlihatkan laju pertumbuhan penduduk tahun $\mathrm{n}$ yang dapat disesuaikan dengan waktu simulasi. 


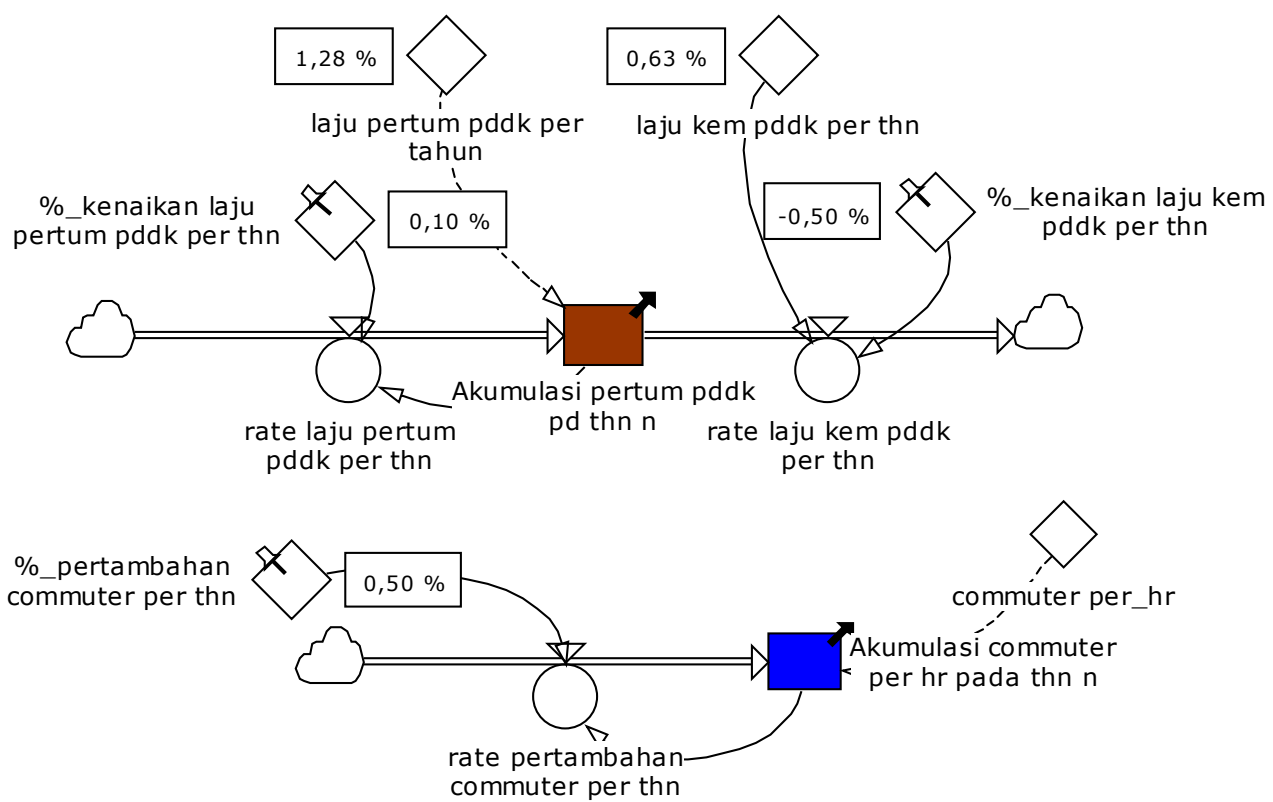

Gambar 1. Diagram Alir Laju pertumbuhan penduduk (Rahman, 2011)

Persamaan matematis dari Gambar 1 disajikan pada Tabel 2 berikut ini.

Tabel 2. Persamaan Matematis Laju Pertumbuhan Penduduk

\begin{tabular}{|c|c|c|}
\hline Variabel & Satuan & Definisi \\
\hline laju pertumbuhan penduduk & $\% /$ thn & 1,28 \\
\hline$\%$ kenaikan laju pertumbuhan penduduk & $\% /$ thn & 0,1 \\
\hline laju kematian penduduk & $\% /$ thn & 0,63 \\
\hline$\%$ kematian penduduk & $\% /$ thn & $-0,5$ \\
\hline$\%$ pertambahan commuter & $\% /$ thn & 0,5 \\
\hline rate laju pertumbuhan penduduk & jiwa & $\begin{array}{l}\text { (Akumulasi pertum pddk pd thn } \\
n * \% \_ \text {kenaikan laju pertum pddk per } \\
\text { thn)/365,24 }\end{array}$ \\
\hline rate laju kematian penduduk & jiwa & $\begin{array}{l}\text { (\%_kenaikan laju kem pddk per thn*laju } \\
\text { kem pddk per thn)/365,24 }\end{array}$ \\
\hline rate laju pertumbuhan commuter & jiwa & $\begin{array}{l}\text { (Akumulasi commuter per hr pada thn } \\
n * \% \text { pertambahan commuter per } \\
\text { thn)/365,24 }\end{array}$ \\
\hline Akumulasi pertum pddk pd thn $n$ & jiwa & dt laju pertumbuhan penduduk * \\
\hline Akumulasi commuter per hr pada thn $\mathrm{n}$ & jiwa & dt commuter per hari \\
\hline
\end{tabular}

Sumber : (Rahman, 2011)

Untuk dapat mengetahui jumlah sampah yang dihasilkan oleh penduduk kota Medan setiap harinya maka selanjutnya Rahman (2011) membangun model laju pertumbuhan sampah berdasarkan komposisinya serta laju timbulan sampah perorang perhari seperti yang disajikan pada Gambar 2 berikut ini. 


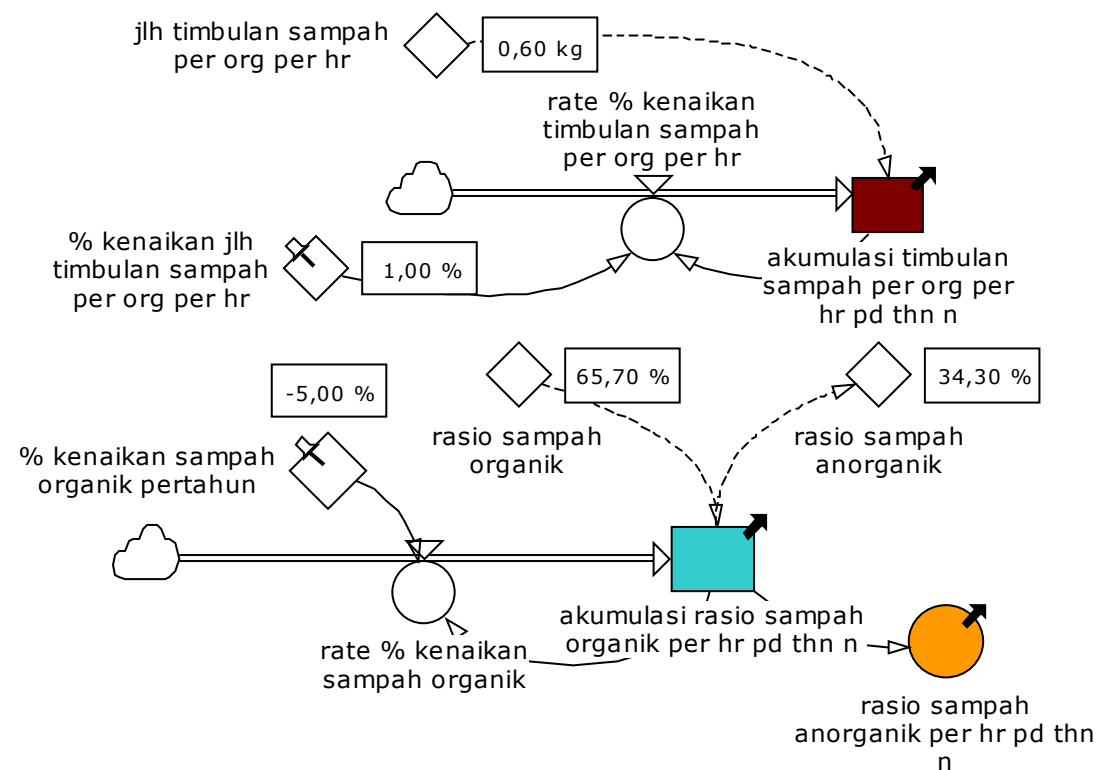

Gambar 2. Diagram Alir Laju Timbulan Sampah (Rahman, 2011)

Persamaan matematis dari Gambar 2 disajikan pada Tabel 3 berikut ini.

Tabel 3. Persamaan Matematis Laju Timbulan Sampah

\begin{tabular}{|c|c|c|}
\hline Variabel & Satuan & Definisi \\
\hline jlh timbulan sampah per org per $\mathrm{hr}$ & $\mathrm{kg} / \mathrm{hr}$ & 0,6 \\
\hline$\%$ kenaikan jlh timbulan sampah per org per hr & $\%$ & 0,1 \\
\hline rate \% kenaikan timbulan sampah per org per hr & jiwa & $\begin{array}{l}\text { (\% kenaikan jlh timbulan sampah per } \\
\text { org per hrakumulasi timbulan sampah } \\
\text { per org per hr pd thn } n \text { ) } / 365,24\end{array}$ \\
\hline $\begin{array}{l}\text { akumulasi timbulan sampah per org per hr pd thn } \\
\mathrm{n}\end{array}$ & $\mathrm{kg} / \mathrm{hr}$ & $\begin{array}{l}\mathrm{dt} \text { rate \% kenaikan timbulan sampah } \\
\text { per org per } \mathrm{hr}+\mathrm{jlh} \text { timbulan sampah } \\
\text { per org per } \mathrm{hr}\end{array}$ \\
\hline$\%$ kenaikan sampah organik pertahun & $\%$ & $-4,447$ \\
\hline rasio sampah organic & $\%$ & 68,8 \\
\hline rasio sampah anorganik & $\%$ & 31,20 \\
\hline rate \% kenaikan sampah organic & $\%$ & $\begin{array}{l}\text { (\% kenaikan sampah organik } \\
\text { pertahun*akumulasi rasio sampah } \\
\text { organik per hr pd thn } \mathrm{n} \text { )/365,24 }\end{array}$ \\
\hline akumulasi rasio sampah organik per $\mathrm{hr} p d$ thn $\mathrm{n}$ & $\%$ & $\begin{array}{l}\mathrm{dt} \text { rate } \% \text { kenaikan sampah organik + } \\
\text { rasio sampah organik }\end{array}$ \\
\hline rasio sampah anorganik per $\mathrm{hr} p \mathrm{~d}$ thn $\mathrm{n}$ & $\%$ & $\begin{array}{l}100 \text {-akumulasi rasio sampah organik } \\
\text { per hr pd thn } n\end{array}$ \\
\hline
\end{tabular}

Sumber : (Rahman, 2011)

Hasil simulasi jumlah timbulan sampah perkotaan di kota Medan dalam kurun waktu 2012 - 2032 dapat dilihat pada Tabel 4 berikut ini. 
Tabel 4. Jumlah Timbulan Sampah Perkotaan Kota Medan 2012 - 2032

\begin{tabular}{|c|c|c|c|c|}
\hline Tahun & Jumlah Peduduk & $\begin{array}{c}\text { Timbulan } \\
\text { Sampah/org/hr }\end{array}$ & $\begin{array}{c}\text { Total Timbulan } \\
\text { Sampah / hari } \\
\text { (Ton/ Hr) }\end{array}$ & $\begin{array}{c}\text { Total Timbulan } \\
\text { Sampah /tahun } \\
\text { (KTon/ Tahun) }\end{array}$ \\
\hline 2012 & $2,506,142$ & 0.60 & $1,309.96$ & 478.45 \\
\hline 2013 & $2,533,916$ & 0.60 & $1,316.57$ & 480.87 \\
\hline 2014 & $2,562,109$ & 0.60 & $1,322.78$ & 483.13 \\
\hline 2015 & $2,590,728$ & 0.60 & $1,328.55$ & 485.24 \\
\hline 2016 & $2,619,780$ & 0.60 & $1,333.85$ & 487.18 \\
\hline 2017 & $2,649,273$ & 0.60 & $1,338.63$ & 488.92 \\
\hline 2018 & $2,679,216$ & 0.60 & $1,342.84$ & 490.46 \\
\hline 2019 & $2,709,616$ & 0.60 & $1,346.45$ & 491.78 \\
\hline 2020 & $2,740,481$ & 0.60 & $1,349.41$ & 492.86 \\
\hline 2021 & $2,771,821$ & 0.61 & $1,351.65$ & 493.68 \\
\hline 2022 & $2,803,643$ & 0.61 & $1,353.14$ & 494.22 \\
\hline 2023 & $2,835,956$ & 0.61 & $1,353.80$ & 494.46 \\
\hline 2024 & $2,868,770$ & 0.61 & $1,353.57$ & 494.38 \\
\hline 2025 & $2,902,093$ & 0.61 & $1,352.40$ & 493.95 \\
\hline 2026 & $2,935,935$ & 0.61 & $1,350.20$ & 493.15 \\
\hline 2027 & $2,970,305$ & 0.61 & $1,346.90$ & 491.94 \\
\hline 2028 & $3,005,214$ & 0.61 & $1,342.43$ & 490,00 \\
\hline 2029 & $3,040,670$ & 0.61 & $1,336.69$ & 488.21 \\
\hline 2030 & $3,076,684$ & 0.61 & $1,329.60$ & 485.62 \\
\hline 2031 & $3,113,266$ & 0.61 & $1,321.05$ & 482.50 \\
\hline 2032 & $3,150,428$ & 0.61 & $1,310.96$ & 478.81 \\
\hline
\end{tabular}

Sumber : Hasil Simulasi Model (Rahman, 2011)

Tabel 4 diatas memperlihatkan bahwa timbulan sampah yang dihasilkan masyarakat kota Medan berfluktuasi secara dinamis terhadap waktu akibat adanya pertambahan penduduk dan jumlah sampah yang dihasilkan oleh setiap penduduk perharinya. Dari Tabel diatas juga terlihat bahwa jumlah timbulan sampah perkotaan yang dihasilkan masyarakat kota Medan selama 1 tahun berada pada kisaran 478,45 KTon/tahun - 494,46 KTon/tahun. Hal ini tentunya akan berimplikasi pada pemilihan alternatif teknologi pengelolaan yang akan disimulasikan pada tahapan selanjutnya (Tabel 1) yaitu alternatif teknologi yang memiliki kapasitas pengolahan maksimal sebesar 500000 Ton/tahun (Tabel 1)

\section{VALUASI EKONOMI ALTERNATIF TEKNOLOGI PENGELOLAAN SAMPAH PERKOTAAN}

Valuasi ekonomi terhadap alternatif teknologi pengelolaan (Tabel 1) dilakukan dengan cara mengembangkan diagram alir dan model yang dapat merepresentasikan kinerja dinamis setiap alternatif teknologi pengelolaan sampah perkotaaan tersebut. Pengembangan model tersebut dapat dilihat pada Gambar 3 berikut ini. 


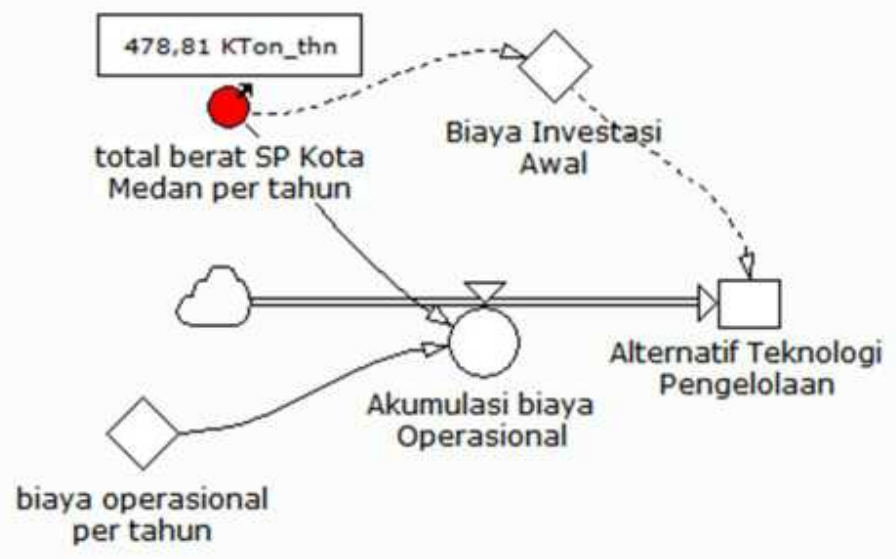

Gambar 3. Diagram Alir Valuasi Ekonomi Alternatif Teknologi Pengelolaan

Hasil simulasi fungsi biaya alternatif teknologi pengelolaan sampah perkotaan dalam rentang waktu 2012 sampai dengan 2032 memperlihatkan bahwa apabila teknologi Biodrying yang dikombinasikan dengan Incenerator atau Gasifikasi diterapkan sebagai teknologi untuk mengelola sampah di Kota Medan maka teknologi tersebut merupakan teknologi yang paling sedikit membutuhkan biaya operasional setiap tahunnya. Teknologi ini hanya membutuhkan biaya operasional rata-rata pertahun sebesar 10,907 juta Euro. Sedangkan teknologi Aerobic MBT (Mechanical Biological Treatment) tanpa proses produksi RDF (Refuse Derivative Fuel) merupakan teknologi yang paling banyak membutuhkan biaya operasional pertahunnya dengan nilai sebesar 15.808 juta Euro. Hasil simulasi terhadap fungsi biaya operasional setiap alternatif teknologi dapat dilihat pada Tabel 5.

Tabel 5 juga memperlihatkan bahwa alternatif teknologi Incenerationberada pada urutan kedua dari sisi rendahnya biaya operasional dengan nilai rata-rata sebesar 11.605 juta Euro. Sedangkan teknologi Aerobic MBT dengan produksi RDF berada pada urutan ketiga dengan rata-rata biaya operasional sebesar 13.509 juta Euro.Hasil simulasi tersebut juga mengindikasikan bahwa dalam konteks biaya operasional ke dua teknologi yang termasuk kedalam kategori Thermal Treatment (Biodrying yang dikombinasikan dengan Incenerator atau Gasifikasi dan Inceneration) lebih efisien dibandingkan dengan teknologi Biological Treatment (Aerobic MBT tanpa proses produksi RDF dan Aerobic MBT dengan produksi RDF)

Tabel 5. Hasil Simulasi Fungsi Biaya Operasional Alternatif Teknologi 2012 - 2032

\begin{tabular}{ccccc} 
Tahun & $\begin{array}{c}\text { Aerobic MBT } \\
\text { without RDF } \\
\text { recovery }\end{array}$ & $\begin{array}{c}\text { Aerobic MBT } \\
\text { with RDF } \\
\text { recovery }\end{array}$ & Incineration & $\begin{array}{c}\text { Biodrying + } \\
\text { incineration or } \\
\text { gasification }\end{array}$ \\
\cline { 2 - 5 } & \multicolumn{4}{c}{ Biaya Operasional } \\
\hline 2012 & $15,480,900.97$ & $13,229,493.44$ & $11,437,277.77$ & $10,709,832.50$ \\
& & & QE Journal | Vol.01 - No.01 - 42
\end{tabular}




\begin{tabular}{ccccc}
\hline \multirow{2}{*}{ Tahun } & $\begin{array}{c}\text { Aerobic MBT } \\
\text { without RDF } \\
\text { recovery }\end{array}$ & $\begin{array}{c}\text { Aerobic MBT } \\
\text { with RDF } \\
\text { recovery }\end{array}$ & Incineration & $\begin{array}{c}\text { Biodrying + } \\
\text { incineration or } \\
\text { gasification }\end{array}$ \\
\cline { 2 - 6 } & \multicolumn{5}{c}{ Biaya Operasional } \\
\hline 2017 & $15,819,636.88$ & $13,518,957.53$ & $11,611,906.75$ & $10,914,151.17$ \\
2022 & $15,991,107.78$ & $13,665,486.63$ & $11,699,877.07$ & $11,017,366.56$ \\
2027 & $15,917,342.94$ & $13,602,451.47$ & $11,662,068.10$ & $10,972,981.78$ \\
2032 & $15,492,548.05$ & $13,239,446.36$ & $11,443,301.11$ & $10,716,867.15$ \\
\hline Rata-rata & $15,808,066.83$ & $13,509,070.44$ & $11,605,822.31$ & $10,907,112.97$ \\
\hline
\end{tabular}

Sumber : Hasil Simulasi Gambar 3.

Namun hal diatas akan sangat kontradiktif dengan biaya investasi awal yang dibutuhkan untuk menerapkan setiap alternatif teknologi diatas. Dari sisi biaya investasi awal ternyata kedua teknologi Biological Treatmentmemiliki nilai investasi awal yang lebih rendah dibandingkan dengan kedua teknologi Thermal Treatment diatas. Untuk mengadopsi Teknologi Aerobic MBT tanpa proses produksi RDF dan Aerobic MBT dengan produksi RDF dibutuhkan biaya sebesar 48,278 juta Euro dan 56,934 juta Euro. Sedangkan untuk mengadopsi teknologi Thermal Treatment yang terdiri dari teknologi Biodrying yang dikombinasikan dengan Incenerator atau Gasifikasi dan Incenerationdibutuhkan biaya sebesar 61,233 juta Euro dan 205,844 juta Euro.

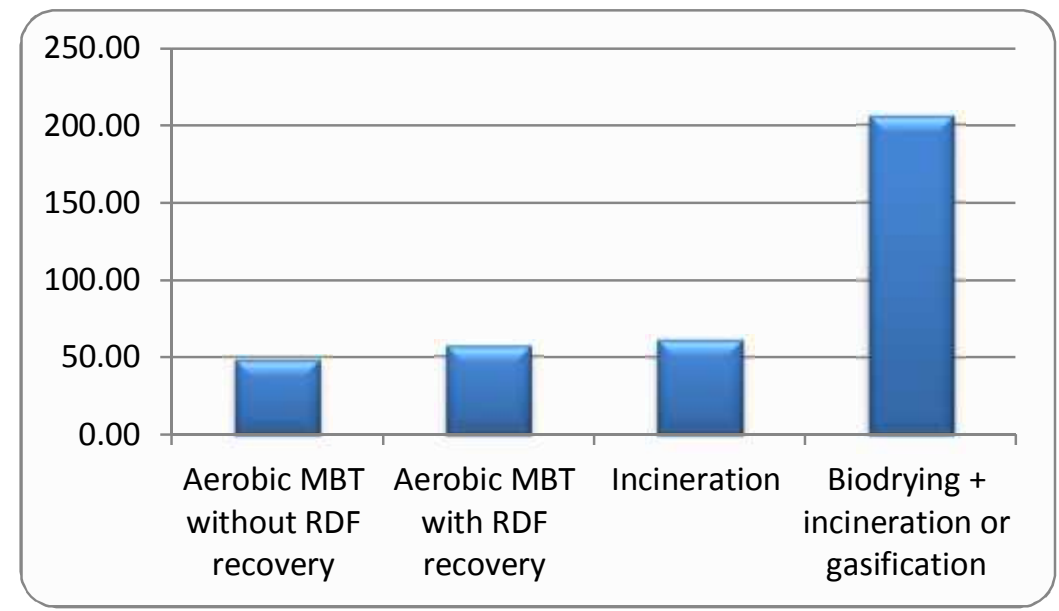

Gambar 4. Biaya Investasi Awal Alternatif Teknologi Pengelolaan Sampah

\section{PEMBAHASAN DAN KESIMPULAN}

Hasil simulasi fungsi biaya alternatif teknologi pengelolaan yang dikombinasikan dengan data timbulan sampah perkotaan di Kota Medan secara eksplisit memberikan gambaran bahwa teknologi yang cukup layak diterapkan untuk mengelola sampah perkotaan terdiri atas : (1) Teknologi Aerobic MBT tanpa proses produksi RDF; (2) Aerobic MBT dengan produksi RDF dibutuhkan dan (3) Incenerationyang membutuhkan biaya dibawah 75 juta Euro untuk mengelola total 
sampah perkotaan sebesar 500 KTon pertahun. ke 3 teknologi ini juga memiliki nilai biaya operasional pada rentang yang tidak jauh berbeda. Namun tentunya hasil valuasi ekonomi ini saja tidaklah cukup untuk dijadikan sebagai acuan dalam menentukan kebijakan yang berkaitan dengan penerapan alternatif teknologi pengelolaan sampah perkotaan. Hal ini didasarkan atas pertimbangan keberlanjutan dari teknologi itu sendiri di masa depan. McDougall et al. (2001) mendefiniskan bahwa suatu sistem pengelolaan sampah perkotaan baru dapat dikatakan berkelanjutan apabila sistem tersebut : (1) berwawasan lingkungan; (2) terjangkau secara ekonomis; (3) diterima masyarakat. Dari pernyataan diatas tentunya perlu dilakukan juga dilakukan kajian yang komprehensif yang berkaitan dengan kontribusi lingkungan dari setiap alternatif teknologi serta kajian sosial yang dapat digunakan untuk mengukur tingkat akseptabilias masyarakat terhadap teknolgi pengelolaan sampah perkotaan.

\section{DAFTAR PUSTAKA}

Dubois, M., González, A.M.M., Knadel, M. 2004. Municipal solid waste treatment in the $E U$, Center for Environmental Studies, Aarhus University. Denmark.

EC (European Commission). 2000. A Study on the Economic Valuation of Environmental Externalities from Landfill Disposal and Incineration of Waste. Final Appendix Report. Brussels : Belgia.

Economopoulos, Alexander P. 2009. Technoeconomic aspects of alternative municipal solid wastes treatment methods, Waste Management Journal, Elsevier Ltd doi:10.1016/j.wasman.2009.11.004., www.elsevier.com/locate/wasteman.

Eunomia Research and Consulting, 2000. Economic analysis of options for managingbiodegradable municipal waste. Final Report to European Commission.http://ec.europa.eu/environment/waste/compost/pdf/econanalys is_finalreport.pdf

Eunomia Research and Consulting, 2002. Cost for municipal waste management inthe EU. Final Report to Directorate General Environment, EuropeanCommission. http://ec.europa.eu/environment/waste/studies/eucostwaste_management.ht $\mathrm{m}$

Juniper Consultancy Services Ltd., 2005. Mechanical-Biological-Treatment: A Guidefor Decision Makers/Processes, Policies and Markets.<http://www.juniper.co.uk/Publications/mbt_report.html>

Klein ,A., 2002, Gasification: An Alternative Process for Energy Recovery and Disposal Master Thesis, Department of Earth and Environmental Engineering Foundation School of Engineering and Applied Science, Columbia University.

Last, Steve. 2008. An Introduction to Waste Technologies, Waste Technologies UK Associates.

McDougall, F., White, P., Franke, M. \& Hindle, P. 2001. Integrated solid waste management: a Life Cycle Inventory. $2^{\text {nd }}$ edition. Blackwell Science Ltd. ISBN: 978-0-632-05889-1.

McLanaghan, S.R. B., 2002. Delivering the Landfill Directive: The Role of New and Emerging Technologies, Associates in Industrial Ecology (AilE), United Kingdom. 
Münnich, K., Mahler, C.F., Fricke, K. 2006, Pilot project of mechanical-biological treatment of Waste in Brazil, Waste Management 26 (2006) 150-157, www.elsevier.com/locate/waste-Man

Powersim.2005. Powersim Studio 2005 User Guide. diakses tanggal 25 oktober 2006 pada http://www.powersim.com.

Rahman, H. 2011,.Model Lingkungan Pengelolaan Sampah Perkotaan Studi Kasus Kota Medan, [Disertasi], Sekolah Pasca Sarjana - USU, Medan.

Rahman, H., Armananty, L.D, dan Barlian, E. 2009,.Model Pengelolaan Sampah Perkotaan, Hibah Penelitian Strategis Nasional - Lembaga Penelitian - UNIMED.

Schübeler, Peter., Wehrle, Karl. \& Christen , Jürg. 1996. Conceptual Framework for Municipal Solid Waste Managementin Low-Income Countries - UNDP/UNCHS (Habitat)/World Bank/SDC Collaborative Programme on Municipal Solid Waste management in Low-Income Countries, $1^{\text {st }}$ edition, SKAT (Swiss Centre for Development Cooperation in Technology and Management), Switzerland.

Tasrif, M. 2005. Analisis Kebijakan Menggunakan Model System Dynamics. Bandung: Institut Teknologi Bandung.

Tsilemou, K., Panagiotakopoulos, D., 2006. Approximate cost functions for solidwaste treatment facilities. Waste Management Research 24, 310-322.

Tsilemou, K., Panagiotakopoulos, D., 2007. Economic assessment of mechanicalbiological treatment facilities. Environmental Research, Engineering andManagement 1 (139), 55-65

WBIO (World Bank Indonesia Office). 2003. Special Focus : Reducing Pollution. Indonesia Environment Monitor, Jakarta Stock Exchange, Jakarta, Indonesia. 